\title{
Media System Dependency and Change in Risk Perception During the COVID-19 Pandemic
}

\author{
Carlos Muñiz \\ Autonomous University of Nuevo León (Mexico)
}

On February 27, 2020 the first case of COVID-19 contagion was detected in Mexico, and by the end of March phase 2 of the epidemic had been declared in the country when local transmission was detected. In a context of crisis and uncertainty like the one described, a risk perception tends to arise among the population that fears to be affected personally, to a large extent due to the influence exerted by the media by information they provide about the contingency, which derives from the media system dependency that occurs in the population. In order to determine the risk perception present in view of the COVID-19 pandemic, as well as the influence that media consumption had on the population's attitude, an online analytical survey was carried out with 630 Mexican respondents. The results present a population with a relatively low risk perception, but with a moderate dependency when it comes to getting information about everything that has to do with the pandemic. In addition, it is possible to observe that this dependency tends to generate an increase, in an indirect manner, in the risk perception through the consumption of television, digital press and Facebook.

Keywords: risk perception, traditional media, social networks, media system dependency, COVID-19.

\footnotetext{
$\mathrm{A}$ lthough by January 23, 2020 Mexico's Health Department had already reported the existence of five cases suspected of COVID-19 in the country, it was not until February 27 that the first case of confirmed contagion was officially reported. But it was from the moment that the WHO (The World Health Organization) declared the worldwide pandemic on March 11 that the Mexican government began to make action decisions in the face of the crisis. Thus, March 16 the Secretary of Public Education announced suspension of onsite classes in all the school levels and on March 23 the government ask for a voluntary confinement among the population in their homes and the development of social dis-
} 
tancing in public places. Finally, on March 24, it was announced that the country was entering phase 2 of the pandemic, when local transmission of the disease was confirmed, in addition of the death of four people affected by COVID-19. ${ }^{1}$

In situations such as the one just described, which can be considered as a threat for public health, but also during a national and international crisis at different levels (such as the social, economic, political, etc.), the population usually tends to set up protection actions (Garfin, Silver, and Holman, 2020; Muñiz, 2011). For this aim, it is normal for people to increase their interest in seeking information and guidance as to the way they should act, and in these contexts media consumption and exposure is enhanced (Farré, 2005; Morton and Duck, 2001). It is precisely this relation between the public and the media in crisis and uncertainty moments that has been explained from the viewpoint of the media system dependency theory (Ball-Rokeach and DeFleur, 1976), which claims that the media become the primary sources of information for the citizens in moments when there are conflicts within the social system, either as the result of natural disasters, public health or due to human decisions and actions (Hindman, 2004; Lin, Xu, and Dam, 2020; Morton and Duck, 2001; Muñiz, 2011).

To a large extent, these actions conducted by the citizens in view of crisis situations are associated with the increase of a personal risk perception, resulting from the threat existing in the social context. This perception is a subjective judgment made at an individual level about the possible negative consequences of a crisis such as the coronavirus disease (Yoo, 2019; Yoo, Paek, and Hove, 2020), due to the fact that the existence of a concrete and strong probability is perceived of an occurrence that presupposes a risk for the individual (Farré, 2005). The research conducted so far has determined that this perception tends to increase when certain factors appear; one of the key factors among them is the fact that there is sufficient information via the media that reveal the potential dangers of the contingency (Coleman, 1993; Frewer, 2000; Garfin, Silver, and Holman, 2020; Morton and Duck, 2001; Wahlberg and Sjöberg, 2000).

This media effect on the risk perceived by people has been confirmed widely in different studies (Dillard and Yang, 2019; Morton and Duck, 2001; Wahlberg and Sjöberg, 2000; Yoo, 2019), both for the case of the traditional media and the social networks (Duc-Huynh, 2020; Muñiz, 2011; Yoo, 2019). In this sense, it has been detected that great consumption of media can generate and/or increase anxiety and risk perception by people (Coleman, 1993) and even affect their behavior (Morton and Duck, 2001). A kind of impact that increases when the news reflect dramatic situations with which the audience is familiar, such as the case of the COVID-19 pandemic deaths, and when the information is framing with a great degree of personalization (Farré, 2005), using a human interest frame that presents personal consequences of the event (Otieno, Spada, and Renkl, 2013) or with the use of images accompanied by visual aids such as, for example, can be blood (Garfin, Silver, and Holman, 2020). 
Although the contingency resulting from the COVID-19 is relatively recent, there already is evidence about the media consumption increase, as well as the risk perception in view of the disease. In his recent study, Casero-Ripollés (2020) pointed out how in USA media consumption increase among population during the pandemic. Meanwhile, Duc-Huynh (2020) has detected that reception of information on COVID-19 in the case of Vietnam was mainly through the newspapers, television and above all, Facebook. However, only following the social media contributed effectively to increasing risk perception among the population surveyed. Taking these antecedents as a reference, this paper attempts to find out whether media system dependency modified risk perception among the Mexican citizens in view of the COVID-19, as a result of the traditional and social media consumption.

\section{LITERATURE}

\section{Media System Dependency in Crisis Situations}

Both traditional and the new social media have turned into crucial tools for the citizens' access to information about their social reality. This relation tends to become more intense in moments when the population needs more guidance to make decisions, as it can occur with traditional political contexts such as electoral campaigns, but also situations of change and uncertainty, such as can happen during a war, a terrorist attack, a conflict situation or a health crisis (Lin, $\mathrm{Xu}$, and Dam, 2020; Mehrad and Yousefi, 2018). In these contexts dependency of audiences on media information tends to increase, become people more dependent on the messages received by these ways (Hindman, 2004; Tai and Sun, 2007), as it has already been found that happen during the contingency generated by the COVID-19 pandemic in different countries (Casero-Ripollés, 2020; Duc-Huynh, 2020).

During health crisis situations such as the one mentioned above, it is common for the population to tend to increase their levels of search for information on health issues provided by both official and unofficial sources (So, Kuang, and Cho, 2019; Yoo, Paek, and Hove, 2020). Different factors can influence the fact that this search for information increases, among them there are contextual and individual ones, such as the development of emotions such as fear and anxiety, or the risk perception generated by people regarding the possible negative effects of the crisis at an individual level (So, Kuang, and Cho, 2019). This search for information, either via the media or interpersonal relations, as expressed in face to face conversation or that generated by the social media, usually results in greater individual dependency on the media system (Tai and Sun, 2007).

This strong relation that at certain moments is generated between the media and the public has been explained from the theory of media system dependency (Ball-Rokeach and Defleur, 1976), which is found half-way between the study of media effects and the use and gratifications approaches (Mehrad and Yousefi, 2018). The theory's main postulate holds that media become primary sources of information in conflictive moments within the social system, either resulting 
14 from natural disasters or due to human intervention (Ball-Rokeach and Defleur, 1976; Hindman, 2004). This action of the media is framed from the theory in the interrelation existing between the media, society and the audience, which in addition allows understanding media use by individuals in crisis situations (Hindman, 2004; Tai and Sun (2007).

In developing their theory, DeFleur and Ball-Rokeach (1989) pointed out that this relation among the actors can entail the existence of two planes of dependency: at the macro level, as it is the case of the relations between media system and political system, and that which manifests at the micro level, where the effects of the media system are presented at an individual level. On this plane, people are exposed to information contents to fulfill certain psychological needs, including those of vigilance and observation and thus obtain information to make subsequent decisions (Hindman, 2004; Lin and Lagoe, 2013; Lin, Xu, and Dam, 2020). Such a strong relation of dependency leads, therefore, to an increase in processing the news and information broadcast by the media, and in a complementary manner, to an increase of the possibility of being impacted broadly in the development of further attitudes and behaviors (Morton and Duck, 2001).

Nevertheless, the level of dependency is not uniform for the different individuals, nor is it manifested in the search for information itself (Mehrad and Yousefi, 2018). In this sense, along with the existence of a generic dependency on the media system, there is also a particular dependency on different media, both traditional and social ones, which will depend on the characteristics of each individual (Lin and Lagoe, 2013; Mehrad and Yousefi, 2018), such as can be the levels of education (Mehrad and Yousefi, 2018). Thus, greater dependency can impact by increasing the levels of selective exposure to contents, programs, and media to obtain information about a health crisis (Lin and Lagoe, 2013). This to understand the social environment, seeking orientations in order to relate with other people and/or to act by evading problems of daily stress or social events (Ball-Rokeach and Defleur, 1976; Mehrad and Yousefi, 2018; Wilkin and Ball-Rokeach, 2006).

The media system has the capacity to reinforce or change certain attitudes and behaviors at a personal level through the dissemination of information (Ball-Rokeach and DeFleur, 1976; Hindman, 2004). So it has been pointed out that dependency can generate in people greater knowledge about the crisis (Lin, $\mathrm{Xu}$, and Dam, 2020), the development of emotions, such as fear and anxiety (Mehrad and Yousefi, 2018) or undergoing certain health behaviors (Lin and Lagoe, 2013). Previous studies have also revealed the impact of dependency on the development of personal risk perception in crisis situations (Garfin, Silver, and Holman, 2020; Morton and Duck, 2001), such as for example what Lin and Lagoe (2013) detected in the case of the H1N1pandemic.

\section{Risk Perception in Crisis Situations}

Crisis situations lead to the generation of scenarios where the perception of threat by the population tends to increase (Garfin, Silver, and Holman, 2020; Muñiz, 2011; Yoo, 2019; Yoo, Paek, and Hove, 2020). In these contexts, it is common for a sensation of fear to increase among the population before the 
situation at hand, that is, a negative emotion associated with others such as anxiety or concern before the uncertainty that accompanies the crisis. This emotion usually tends to emerge when the context is perceived as unfavorable, to the extent that the person feel that the risk of being affected by the threat is real and strong (Dillard and Yang, 2019; Yang, Dillard, and Li, 2018). Therefore, it is possible to observe a clear relation between the development of negative emotions and the increase of risk perception, which grows in situations of crisis and uncertainty.

This perception has been described as a sensation resulting from the subjective judgments that individuals make about possible negative consequences, such as injuries, diseases or death itself, which the crisis at hand can entail (Yoo, 2019; Yoo, Paek, and Hove, 2020). It implies, therefore, a "quantifiable probability of an adverse event to occur with tragic or negative consequences for human beings" (Farré, 2005: 103). However, this is an ambivalent concept, since it encompasses various aspects, such as the change of feelings, beliefs, cognitions and attitudes (Coleman, 1993). That is why it is possible to find definitions such as risk judgment, which refers solely to the la perceptual or cognitive dimension (Coleman, 1993), or risk perception, a multidimensional concept that also includes the affective aspect (Morton and Duck, 2001) and constitutes a step prior to possible preventive behavior changes in a crisis situation (Yoo, Paek, and Hove, 2020).

For this sensation to occur in the individual, it is necessary for different scenarios to be present. Risk must be real, there must be a possibility of danger, in addition, it is necessary for its real dimension to be unknown, that is, there must be uncertainty about its effect. And, finally, the threat must imply some tangible characteristic that can influence negatively and unpredictably on the people affected by the crisis (Farré, 2005). In the case of COVID-19, the risk is not only real due to the nature of the disease itself, which has been widely proved by the number of contagions, but also due to certain measures that were taken as prevention mechanisms. Decisions adopted in different countries, which ranged from mild measures of social distancing to the most severe ones such as home confinement, revealed the seriousness of the situation. Thus, the possibility of danger became something tangible, but it was enveloped in a certain uncertainty about the actual possibility of contagion.

The risk perception kept by people in crises and uncertainty situations appears in two ways (Tyler and Cook, 1984). In this sense, from the hypothesis of impersonal impact, the existence of two different levels of risk perception has been set out: the one manifested at the social level and the one that appears at an individual level (Yoo, Paek, and Hove, 2020). While the individual one implies the sensation that individuals have of being affected personally by the existing danger, the social level manifests itself in the feeling that the crisis can affect other people more than it can the respondents, whether they are known or unknown people (Morton and Duck, 2001). At any rate, risk perception tends to increase as certain amplifying stations increase the social feeling of the risk (Dillard and Yang, 2019; Yang, Dillard, and Li, 2018), among them interpersonal networks and the media. 


\section{Media Consumption As an Explanatory Factor of Risk PERCEPTION}

There are different factors that can determine the generation of greater or lesser risk perception among the population in view of given conflictive situations. For example, Coleman (1993) points out that, in everyday activities or occasional situations, such as driving a car, ones can be perceived as more dangerous. That is to be expected, therefore, in a crisis such as the COVID-19 pandemic, which disrupts social peace and normalcy. In addition, greater geographic proximity with a place that is in crisis generates greater levels of feelings of threat (Dillard and Yang, 2019; Duc-Huynh, 2020). On the other hand, certain factors of an intrapersonal nature increase this perception, such as the existence of personal experiences, educational level (Lin and Lagoe, 2013; Sim et al., 2018) or a person's gender, women being more prone to presenting greater levels of risk perception (Dillard and Yang, 2019).

Furthermore, perception increases when the dangers are highly and effectively publicized or broadcast by amplifying stations such as, for example, the media (Coleman, 1993; Frewer, 2000; Wahlberg and Sjoberg, 2000). The research conducted to date has detected ample evidence of the impact that consumption of information contents of the media has on personal risk perception (Muñiz, 2011; Sim et al., 2018; Wahlberg and Sjoberg, 2000; Yoo, Paek, and Hove, 2020), especially when the news is accurate and deals with issues that can affect the audience, when there is an identification with the information source or when it is broadcast through certain media, such as television (Morton and Duck, 2001). It has been detected like this during several health crises, such as during the Ebola or Zika outbreaks in the USA (Dillard and Yang, 2019; Yang, Dillard, and Li, 2018) or the H1N1 pandemic in Mexico (Muñiz, 2011), where media consumption caused the fear of contagion to increase.

Certain aspects related with the content of the messages can increase the effect on risk perception. For example, messages elaborated with a high degree of personalization by means of news frames that can be easily coupled within the interpretative frameworks or schemes that the population uses in their daily life (Farré, 2005). That is the case of human interest frame, which focuses on the personal consequences of the event (Otieno, Spada, and Renkl, 2013) with the accompaniment of images with a high emotional charge (Garfin, Silver, and Holman, 2020). That adds to the effect that consumption of a high volume of news on a certain risk issue has (Coleman, 1993), something that can grow when the media approach ruptures issues on a large scale and family situations that are dramatic to a large portion of the audience are reflected. That was the case of the Ebola outbreak in the USA, where anxiety and concern were increased by an excess of media consumption (Garfin, Silver, and Holman, 2020).

Risk perception is affected by different communicative ways. Thus, mass communication normally affects more the perception of a risk at the social level (Coleman, 1993; Morton and Duck, 2001; Yoo, Paek, and Hove, 2020). On the other hand, getting information from highly credible sources, as it can be with interpersonal communication, tends to cause the levels of risk perception to in- 
crease at an individual level (Castillo, Martínez, and Batllori, 2007; Frewer, 2000; Wahlberg and Sjoberg, 2000). It is a type of relation where the information is obtained by means of direct contact with other people, through the exchange of beliefs and opinions, similar to that achieved in the virtual world by the social networks (Lin, Xu, and Dam, 2020; Yoo, Paek, and Hove, 2020). In this regard, it has been detected that reception of information via Facebook increases risk perception, both individual but above all social perception (Yoo, 2019). Considering these antecedents, the following hypothesis and research questions are set out in this study:

- RQ1: What media were used to obtain information about pandemic?

- RQ2: What level of media system dependency and risk perception were observed among the population?

- H1: Media system dependency increased the citizens risk perception regarding the COVID-19 pandemic.

- RQ3: Did an indirect effect of dependency on risk perception occur by means of the consumption of traditional media and the social networks?

\section{METHOD}

\section{SAMple ANd Procedure}

To carry out the study, an analytical survey was applied, which seeks associations among the variables and their behavioral patterns, to determine their directionality, to prove hypotheses or answer research questions and generate new hypotheses, among other aims (Gill and Johnson, 2010). Considering the situation caused by the pandemic, which made it impossible to conduct face-to-face surveys, it was decided to conduct an online survey among Facebook users in Mexico. This set was chosen since approximately $70.1 \%$ of the Mexican population has access to the Internet, representing 80.6 million users, the majority of whom (88\%) continuously access social networks where Facebook stands out (Instituto Nacional de Estadística y Geografía [INEGI], 2019). Furthermore, although the analytical surveys does not seek to represent a certain population through a probabilistic sample, the data provide by the survey carried out for this study let us to have a close view the way the people in Mexico thinks and what feels about the COVID-19 pandemic and its affects in a personal level and for the country.

To conduct the research, Facebook users from all over the country were invited to participate in an online survey promoted as advertising by this social network. For this purpose, an interaction campaign with a post, which included an image and the link to the survey, publish from the Facebook page of the Political Communication Lab at the Autonomous University of Nuevo León was follow up. The field work was carried out between March 17 and 23, 2020, which coincided with the beginning of the healthcare contingency in Mexico, because it was in this week that the country went from phase 1 to phase 2 of the disease development and expansion. Data collection was conducted through a question- 
18 naire designed on the platform QuestionPro, which allow the survey to be taken only once by the same respondent to prevent ballot box stuffing. To have a sample as significant as possible regarding, we strived to have a broad representation in terms of ages, gender and places of residence.

Overall, the survey was begun by a total of 1,176 respondents, of whom only 660 completed the total number of questions present in the questionnaire. Nevertheless, only the respondents who were of legal age ( $\geq 18$ years) and who were Mexican residents of the country were used of the total amount of data obtained. This fact reduced the final sample to 630 cases, which were the ones with which eventually data analysis was conducted. $48 \%$ of them were men and $52 \%$ were women, with ages ranging from 16 and 77 years $(M=40, E D=15)$. In addition, $59.5 \%$ indicated that their family monthly income ranged between 6,001 and 30,000 Mexican pesos. Of the total number of respondents, $47.5 \%$ answered that they had a university degree, while $36 \%$ indicated that they had post-graduate level education. Finally, $75.2 \%$ of the people surveyed pointed out that they did not belong to any political parties, while the remaining $24.8 \%$ declared that they were close to a political party in the Mexican political spectrum.

\section{Measures}

\section{Perception of Personal Risk}

The risk perception maintained by the survey participants was evaluated using the scale developed by Morton and Duck (2001). The instrument is made up of the following four items: "how important is the coronavirus problem to you?", "how worried are you that you may get the coronavirus?", "in general terms, how likely do you think you are of getting the coronavirus?" and "how much risk do you personally feel in the presence of the coronavirus?" All the questions were measured by means of a Likert-type scale with a five-point answer, ranging from nothing (1) to much (5). The internal consistency of the indicator was high $(\alpha=.79)$.

\section{Media System Dependency}

Regarding this construct, a scale developed taking as reference the one created by Morton and Duck (2001) was used, which measures the degree of agreement with the following statements about media: "they keep us informed about important healthcare issues, such as the coronavirus", "they help us understand the importance that issues such as the coronavirus have in respect of health", "they allow us to decide what healthcare precautions to take in view of situations like that of the coronavirus" and "they make it possible for us to learn how other people cope with important healthcare issues, such as the coronavirus". All the answers were measured by means of a five-point answer Likert scale, ranging from nothing (1) to much (5). The internal consistency of the indicator was high $(\alpha=.89)$. 
Mass Media Exposure

The study participants were asked how much they had followed the different media to obtain information about the coronavirus. Specifically, we evaluated the extent to which they had followed the written press, television, the radio and the digital press, using a Likert scale ranging from nothing (1) to much (5). In addition, we evaluated the extent to which several social networks had been followed, and to this end, they were asked how often they had been informed about the coronavirus during the last few days using Facebook, Twitter and WhatsApp. To this end, a five-point answer Likert scale was used, ranging from never (1) to very often (5).

\section{Control Variables}

Finally, a series of control variables were used, some of them were of a socio-demographic character, while others were of a political nature. Specifically, the respondents were asked about their gender $(1=$ male; $2=$ female $)$ and their age in years. They were also asked to indicate approximately how much their family monthly income amounted to, with a scale that ranged from under 6,000 Mexican pesos (1) to over 30,001 Mexican pesos (4). Moreover, the participants' school level was evaluated, with a scale that ranged from no level (1) to postgraduate studies (7). Finally, respondents were asked to indicate whether they considered themselves close to a Mexican political party. The variable was recoded in nonpartisan (1) and partisan (2).

\section{ANALYSIS OF THE RESULTS}

To answer the first and second research questions of study, the presence of each of the variables of the study among the sample was determined (see Table 1). As to the risk perception among the study respondents $(M=3.29, E D=0.76)$ it was observed that the participants of the study presented a moderate level since they scored sensitively above the theoretical average. The same finding was obtained regarding their media system dependency $(M=3.45, E D=1.13)$, where it was possible to observe a moderate level, though one tending to strong. This level of dependency was expressed mainly by the consumption of certain media to obtain information about the coronavirus. In this regard, and after controlling the influence of socio-demographic variables, differences were detected in respect of the consumption of the different media, $F(6,3440)=9.268, p<.001, \eta_{\text {partial }}{ }^{2}=$ .015 , being the digital press $(M=3.56, E D=1.21)$ and Facebook $(M=3.51, E D=$ 1.28) the most often used media. 
Table 1. Descriptive and partial correlations of the variables used

\begin{tabular}{|c|c|c|c|c|c|c|c|c|c|c|c|}
\hline & $M$ & $D E$ & 1 & 2 & 3 & 4 & 5 & 6 & 7 & 8 & 9 \\
\hline $\begin{array}{l}\text { Written } \\
\text { press }\end{array}$ & 2.04 & 1.19 & - & & & & & & & & \\
\hline Television & 2.52 & 1.32 & $.21^{\star \star \star}$ & - & & & & & & & \\
\hline Radio & 2.06 & 1.17 & $.24^{\star \star \star}$ & $.23^{\star \star \star}$ & - & & & & & & \\
\hline Digital press & 3.56 & 1.21 & $.15^{\star \star \star}$ & $.14^{\star \star \star}$ & .06 & - & & & & & \\
\hline Facebook & 3.51 & 1.28 & .04 & $.13^{\star \star \star}$ & -.02 & $.25^{\star \star \star}$ & - & & & & \\
\hline Twitter & 2.32 & 1.54 & .07 & -.04 & .07 & $.20^{\star * *}$ & $.08^{*}$ & - & & & \\
\hline WhatsApp & 2.65 & 1.31 & .07 & $.18^{\star * \star}$ & .06 & $.10^{*}$ & $.35^{\star \star *}$ & $.14^{\star * \star}$ & - & & \\
\hline $\begin{array}{l}\text { Risk } \\
\text { perception }\end{array}$ & 3.29 & 0.76 & .03 & $.17^{\star \star \star}$ & .06 & $.25^{\star * \star}$ & $.17^{\star \star \star}$ & $.09^{*}$ & $.12^{* *}$ & - & \\
\hline $\begin{array}{l}\text { Media } \\
\text { system } \\
\text { dependency }\end{array}$ & 3.45 & 1.13 & .06 & $.24^{\star \star \star}$ & $.10^{*}$ & $.18^{* * *}$ & $.12^{\star *}$ & $.08^{*}$ & $.16^{\star \star *}$ & $.27^{\star \star *}$ & - \\
\hline
\end{tabular}

Note: $N=630$. All the variables were measured with scales ranging from nothing (1) to much (5).

$$
{ }^{* * *} p<.001 ;{ }^{* *} p<.01 ;{ }^{*} p<.05
$$

Source: Own elaboration.

On the other hand, the existence of the relations among the different variables included in the study was also reviewed (see Table 1). The analysis allowed determining that there were not any collinearity problems in any of the cases, since partial correlations greater than $r=.70$ were not found. In this sense, the strongest association detected was the one existing between media system dependency and risk perception, $\mathrm{r}_{\text {partial }}(624)=.27, p<.001$. The relation between Facebook and WhatsApp consumption to obtain information about the coronavirus, $\mathrm{r}_{\text {partial }}(624)=.25, p<.001$ was also strong. Finally, dependency tended to correlate positively with the consumption of different media: television, $\mathrm{r}_{\text {partial }}(624)=$ $.24, p<.001$, radio, $\mathrm{r}_{\text {partial }}(624)=.10, p=.011$, the digital press, $\mathrm{r}_{\text {partial }}(624)=.18$, $p<.001$, Facebook, $\mathrm{r}_{\text {partial }}(624)=.12, p=.003$, Twitter, $\mathrm{r}_{\text {partial }}(624)=.08, p=.038$, and WhatsApp, $\mathrm{r}_{\text {partial }}(624)=.16, p<.001$. However, it did not correlate with written press.

Regarding the hypothesis sets up in the study, the next step was to carry out the different mediation analyses for their verification. To this end, the media system dependency of respondents during the COVID-19 crisis was used as an independent variable, while the respondents' risk perception was used as the dependent variable and, finally, as mediator variables were used different measurements of media consumption to obtain information about the coronavirus during the beginning of the la pandemic in Mexico. Furthermore, for the calculation of the 
mediation analyses, the effects of the socio-demographic variables as well as the partisanship of respondents were controlled.

This type of analysis allows determining to what extent and how a predicting variable impacts on the criterion variable, as well as whether the mediator variables set out work in attaining this effect. To carry out this analysis, macro PROCESS for SPSS created by Hayes (2013) was used, since it makes it possible to calculate the direct effects and the indirect effects. Specifically, model 4 was used with a bootstrapping of 10.000 samples to determine the indirect effect of the variables described above. The analysis showed as a first finding the existence of a direct effect of the independent variable on the dependent variable, $B=.14$, $S E$ $=.026,95 \% C I[.0897, .1929]$, thus contributing a greater media system dependence to increase the risk perception levels for feeling of being affected during the COVID-19 pandemic in Mexico.

\section{Figure 1. Indirect effect of media system dependency on risk perception}

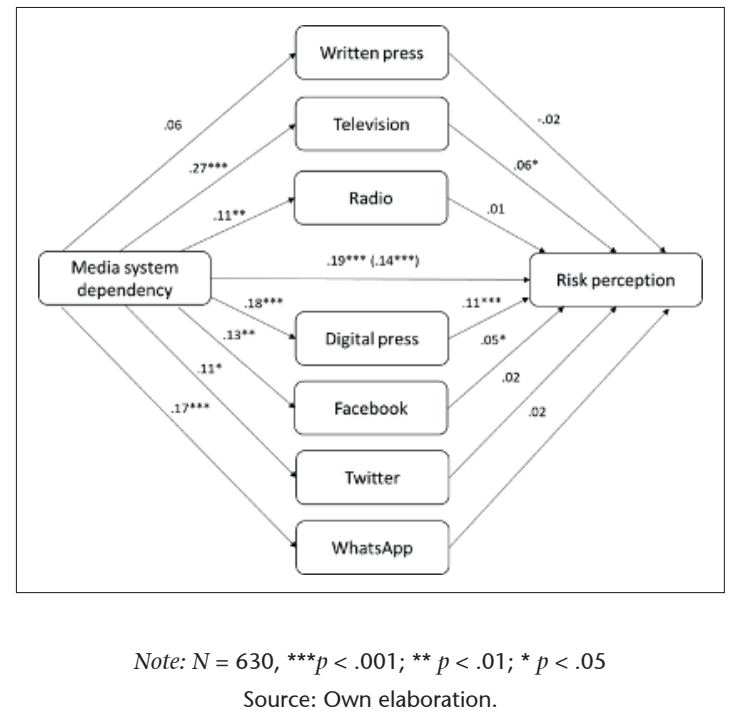

Subsequently, the different items relating to media consumption measured in the survey were introduced in the model as mediator variables (see Figure 1) to determine the existence of possible indirect effects caused by the media exposition. Findings revealed that there was not an indirect effect for most of the consumption variables evaluated. However, a statistically significant indirect effect was detected through three variables. Thus, TV consumption mediated the effect between dependency and risk perception, causing it to increase, $B=.01, S E=$ $.007,95 \%$ IC $[.0021, .0305]$. The presence of an indirect efect was also detected through consumption of digital press, $B=.02, S E=.007,95 \%$ IC $[.0085, .0369]$. Finally, the findings also allowed determining the existence of an indirect effect of Facebook consumption to obtain information about the coronavirus during the beginning of the pandemic, $B=.01, S E=.004,95 \%$ IC $[.0011, .0175]$. 
The contrast of the three effects detected allowed determining that there were no differences at the statistic level among them, therefore it is possible to determine that they became different means to explain the effect of dependency on risk perception. Therefore, it can be concluded that the effect of media system dependency can be explained by means of TV consumption $(\beta=.27, p<.001)$, which in turn caused risk perception to increase $(\beta=.06, p=.02)$. On the other hand, consumption of the digital press increased during the beginning of the pandemic due to media system dependency $(\beta=.18, p<.001)$, which resulted in a greater risk perception $(\beta=.11, p<.001)$. Finally, it was also detected that the greater the dependency the greater the following of the information about the coronavirus on Facebook $(\beta=.13, p=.004)$, which in turn resulted in a greater level of risk perceived $(\beta=.05, p=.03)$.

\section{DISCUSSION AND CONCLUSIONS}

The paper aimed of determining the level of media system dependency held by the Mexican citizens in view of the beginning of the crisis resulting from the COVID-19 pandemic in the country to evaluate its impact on the generation of attitudes that tended to maintain a risk perception of being affected by the disease. In addition, a further objective of the study was to determine the possible existence of indirect effects of dependency through the media consumption developed by the Mexican citizens to obtain information about the COVID-19. Firstly, and regarding the first and second research questions, findings allow observing a moderate dependency together with a moderate risk perception among the population, at least during the initial stage of the pandemic which is the moment when the survey was conducted. As mentioned above, it was not until March 24th that phase 2 was declared regarding the contingency in the country, which entailed adopting more severe measures to act in view of the pandemic, such as voluntary confinement and social distancing.

This result of moderate risk perception diverges from the findings reported by the previous studies which noticed this type of subjective judgment made by individuals about the impact of crises tend to increase in these circumstances (Yoo, 2019; Yoo, Paek, and Hove, 2020). It is possible that the explanation for this lower score, therefore, is due to geographical or territorial factors that were not considered in the survey and that tend to have an impact increasing the sensation of threat (Dillard and Yang, 2019; Duc-Huynh, 2020). On one hand, at the moment in which the study was conducted Mexico was at the initial stage of the disease, with few cases of contagion and death among the population (367 confirmed cases and 5 deaths, according to the Secretary of Health). In addition to that, the main impact of the pandemic was located in distant countries and continents. All these factors could have contributed to decreasing the sensation of how serious the crisis was, moderating the perception of personal risk among the respondents.

Focusing on the first hypothesis of the study, which states that media system dependency increased the citizens risk perception regarding the COVID-19 pandemic, the 
survey findings allow confirming fully the hypothesis set out. Specifically, it was possible to observe a positive and direct effect of dependency on risk perception, the latter increasing as the citizens became more dependent on the messages received through the media that provided information about the pandemic. This result support what has been found in other previous studies, which reveal this media effect at an individual level (Garfin, Silver, and Holman, 2020; Lin and Lagoe, 2013; Morton and Duck, 2001; Muñiz, 2011). Though this result is within the parameters of a line that has already been studied internationally, it should be remembered that there is less evidence in the Mexican context, as well as in the Latin American one, where there has not been developed a detailed study of the effects of risk communication on the basis on the patterns followed here.

In addition, the study reveals the influence of media consumption variables on the generation of opinions about the possible personal consequences of the coronavirus pandemic. Regarding the third research question of the study, which asked: Did an indirect effect of dependency on risk perception occur by means of the consumption of traditional media and the social networks?, it should be concluded that consumption of some media did manage to mediate in the effect of dependency on risk perception. In particular, consumption of television, the digital press and Facebook were the information search habits through which indirect effects occurred in the model studied. Therefore, it can be observed that most consumed media by the people surveyed (excluding the case of WhatsApp), were also those that achieved to mediate so that a greater media system dependency generated an increase on the subjective feelings of threat from citizens before the possible affectation due to the COVID-19 pandemic in the country.

Therefore, it is possible to observe a two-fold form of impact by the media in the generation of a risk attitude among the citizens: on one hand, traditional media via the television and on the other hand the new media via the digital press and Facebook. Although the traditional media seem to be yielding way for the social media as the key tools for obtaining information (Casero-Ripollés, 2020), television maintains an important role in the context of the crisis, thus contributing to a large extent to the increase of the personal sensation of risk in view of the situation reported (Morton and Duck, 2001). Situations of health risk, such as the Ebola or Zika outbreaks that appeared in the USA (Dillard and Yang, 2019; Yang, Dillard, and Li, 2018) or the AH1N1 flu outbreak that spread in 2009 in Mexico (Muñiz, 2011), are examples of how television consumption continues to be crucial for an important part of the population, in addition increasing fear of contagion with the disease among those who showed more consumption of this medium to obtain information.

On the other hand, this paper also allows observing how in the relation between the audience and the media changes have been occurring over time. As opposed to past studies, such as that by Morton and Duck (2001) where it was detected that the major impact on risk perception was that caused by reading the written press, in the present research it is possible to observe how this medium yielded the way to the digital press, which to a large extent is an online version of traditional newspapers. This result is, however, different to previous work by Muñiz (2011) in Mexico, which detected a negative effect of the press on risk 
perception, thus causing it to decrease. This finding necessarily opens a line of research aimed at studying what contents are broadcast by the media regarding the crisis and how these are produced. No wonder it is convenient to remember that the use of certain frames and graphic resources can result in positive response by the audience, but also in negative ones (Garfin, Silver, and Holman, 2020; Otieno, Spada, and Renkl, 2013).

Finally, this paper findings reveal the influence that Facebook exerts on individual risk perceptions before the pandemic, in keeping with the findings of previous studies on the influence of this social network (Yoo, 2019). It is a medium that, due to its nature as a social network, has the capacity to create identities and generate intense relations among the people that are members of the groups that make it up (Lin, $\mathrm{Xu}$, and Dam, 2020). In this sense, the networks can complement and expand, and even replace other connection mechanisms such as those made up by interpersonal communication (Yoo, Paek, and Hove, 2020). The conversation is a practice that has fully proved to be an explanatory variable of the people's risk perception in the context of a crisis (Coleman, 1993; Dillard and Yang, 2019; Lin and Lagoe, 2013; Sim et al., 2018; Yang, Dillard, and Li, 2018). That is why future studies should analyze the relations existing between the use of social networks to obtain information and the dialogical practices developed through mechanisms such as face-to-face or digital interpersonal conversation.

The results obtained no doubt open up a fruitful future line of work, in which emphasis should continue to be laid on the role played by both mass and interpersonal communication through more traditional means of conversation or the new social networks, in the generation of the people's answers in situations of potential risk. To this purpose, it would be convenient to deepen in the study of not only the mechanisms that lead to the generation of risk perception among the people, but also other possible indirect effects at a cognitive, emotional, or affective level (Lin, Xu, and Dam, 2020; Mehrad and Yousefi, 2018; Yoo, Paek, and Hove, 2020) by means of methodological approaches such as panel or experimental surveys. Moreover, it would be interesting to enquire about the impact of communication in these crisis situations on the evaluation of the actors involved with the crisis, such as the governments, politicians or scientists connected with its management (Hindman, 2004).

Carlos Muñiz (carlos.munizm@uanl.mx) hold a PhD in Communication (2007) from the University of Salamanca (Spain). He is currently Professor and Coordinator of the Political Communication Lab (LACOP) at the Faculty of Political Science and International
Relations of the Autonomous University of Nuevo Leon (Mexico). His main research interests focus on the media effects analysis, the impact of communication practices on the generation of political attitudes, and the media framing. 
The research that was the basis for this article was financed with a research project of the Autonomous University of Nuevo León.

\section{References}

Ball-Rokeach, S. and DeFleur, M. (1976). "A Dependency Model of Mass-Media Effects". Communication Research, 3(1), pp. 3-21. DOI: $<$ http://doi.org/10.1177/0093650276003001 $01>$.

Casero-Ripollés, A. (2020). "Impact of COVID-19 on the Media System. Communicative and Democratic Consequences of News Consumption During the Outbreak". El Profesional de la Información, 29(2), e290223. DOI: $<$ https://doi.org/10.3145/epi.2020.mar.23>.

Castillo, D. A.; Martínez, J. S., and Batllori, E. A. (2007). "Los medios de comunicación masiva ante los fenómenos naturales". Espacios Públicos, 11(21), pp. 240-254.

Coleman, C. (1993). "The Influence of Mass Media and Interpersonal Communication on Societal and Personal Risk Judgments". Communication Research, 20(4), pp. 611-628. DOI: <http://doi.org/10.1177/00936 5093020004006>.

DeFleur, M. L. and Ball-Rokeach, S. (1989). Theories of Mass Communication. White Plains, NY: Longman.

Dillard, J. P. and Yang, C. (2019). "Personal, Interpersonal, and Media Predictors of Fear of Ebola". Journal of International Crisis and Risk Communication Research, 2(2), pp. 181-206. DOI: <http://doi.org/10.30658/jicrcr.2.2.2>.

Duc-Huynh, T. L. (2020). "The COVID-19 Risk Perception: A Survey on Socioeconomics and Media Attention". Economics Bulletin, 40(1), pp. 758-764.

Farré, J. (2005). "Comunicación de riesgo y espirales del miedo". Comunicación y Sociedad, (3), pp. 95-119.
Frewer, L. (2000). “Risk Perception and Risk Communication about Food Safety Issues". $\mathrm{Nu}$ trition Bulletin, 25(1), pp. 31-33. DOI: <http:// doi.org/10.1046/j.1467-3010.2000.00015.x>.

Garfin, D. R.; Silver, R. C., and Holman, E. A. (2020). "The Novel Coronavirus (COVID-2019) Outbreak: Amplification of Public Health Consequences by Media Exposure". Health Psychology, 39(5), pp. 355-357. DOI: $<$ http://dx.doi.org/10.1037/hea0000875>.

Gill, J. and Johnson, P. (2010). Research Methods for Managers. London: SAGE.

Hindman, D. B. (2004). "Media System Dependency and Public Support for the Press and President". Mass Communication and Society, 7(1), pp. 29-42. DOI: <https://doi. org/10.1207/s15327825mcs0701_3>.

INEGI. (2019). Encuesta Nacional sobre Disponibilidad y Uso de Tecnologías de la Información en los Hogares (ENDUTIH) 2019. Ciudad de México: INEGI. <https://www.inegi.org.mx/ programas/dutih/2019>.

Lin, C. A. and Lagoe, C. (2013). "Effects of News Media and Interpersonal Interactions on H1N1 Risk Perception and Vaccination Intent". Communication Research Reports, 30(2), pp. 127-136. DOI: <http://dx.doi.org/10.1080 /08824096.2012.762907>.

Lin, C. A.; Xu, X., and Dam, L. (2020). "Information Source Dependence, Presumed Media influence, risk knowledge, and vaccination intention". Atlantic Journal of Communication. DOI: <http://doi.org/10.1080/1545687 $0.2020 .1720022>$.

Mehrad, J. and Yousefi, Z. (2018). "Introducing the Theory of "Media System Dependency" with Emphasis on Its Potential 
Application in Theoretical Framework of Researches in the Field of Information Science and Knowledge". International Journal of Information Science and Management, 16(1), pp. $1-14$.

Morton, T. and Duck, J. (2001). "Communication and Health Beliefs. Mass and Interpersonal Influences on Perceptions of Risk to Self and Others". Communication Research, 28(5), pp. 602-626. DOI: <http://doi.org/10.1 177/009365001028005002>.

Muñiz, C. (2011). "Búsqueda de información durante tiempos de crisis. Efectos de la comunicación interpersonal y masiva en la percepción de riesgo personal ante la gripe AH1N1". Revista de Ciencias Sociales, 17(1), pp. 9-21. DOI: <http://dx.doi.org/10.31876/rcs. v17i1.25542>.

Otieno, C.; Spada, H., and Renkl, A. (2013). "Effects of News Frames on Perceived Risk, Emotions, and Learning". PloS One, 8(11), e79696. DOI: <http://dx.doi.org/10.1371/ journal.pone.0079696>.

Sim, T.; Hung, L.; Su, G., and Cui, K. (2018). "Interpersonal Communication Sources and Natural Hazard Risk Perception: A Case Study of a Rural Chinese Village". Natural Hazards, 94, pp. 1307-1326. DOI: <https://doi. org/10.1007/s11069-018-3478-6>.

So, J.; Kuang, K., and Cho, H. (2019). “Information Seeking upon Exposure to Risk Messages: Predictors, Outcomes, and Mediating Roles of Health Information Seeking". Communication Research, 46(5), pp. 663-687. DOI: <https:// doi.org/10.1177/0093650216679536>.

Tai, Z. and Sun, T. (2007). "Media Dependencies in a Changing Media En- vironment: The Case of the 2003 SARS Epidemic in China". New Media and Society, 9(6), pp. 987-1009. DOI: <http://doi. org/10.1177/1461444807082691>.

Tyler, T. and Cook, F. (1984). "The Mass Media and Judgments of Risk: Distinguishing Impact on Personal and Societal Level Judgments". Journal of Personality and Social Psychology, 47(4), pp. 693-708. DOI: <http://doi. org/10.1037/0022-3514.47.4.693>.

Wahlberg, A. A. and Sjöberg, L. (2000). "Risk Perception and the Media". Journal of Risk Research, 3(1), pp. 31-50. DOI: <http:// doi.org/10.1080/136698700376699>.

Wilkin, H. and Ball-Rokeach, S. (2006). "Reaching at Risk Groups. The Importance of Health Storytelling in Los Angeles Latino media". Journalism, 7(3),pp.299-320. DOI:<http:// doi.org/10.1177/1464884906065513>.

Yang, C.; Dillard, J. P., and Li, R. (2018). "Understanding Fear of Zika: Personal, Interpersonal, and Media Influences". Risk Analysis, 38(12), pp. 2535-2545. DOI: <http://doi. org/10.1111/risa.12973>.

Yoo, W. (2019). "How Risk Communication Via Facebook and Twitter Shapes Behavioral Intentions: The Case of Fine Dust Pollution in South Korea". Journal of Health Communication, 24, pp. 663-673. DOI: <https://doi.org/10 $.1080 / 10810730.2019 .1655607>$.

Yoo, W.; Paek, H., and Hove, T. (2020). "Differential Effects of Content-Oriented 'versus' User-Oriented Social Media on Risk Perceptions and Behavioral Intentions". Health Communication, 35(1), pp. 99-109. DOI: <http://doi.org/10.1080/10410236.201 8.1545169>. 